María Jesús Gallardo Castillo

Profesora Titular de Derecho Administrativo.

Universidad de Jaén

\title{
La distribución constitucional de competencias en materia de turismo y su tratamiento en las Leyes Autonómicas: su promoción y ordenación
}

SUMARIO: 1. CONSIDERACIONES GENERALES. 2. LA PROMOCIÓN TURÍSTICA. 2.1. CONSIDERACIONES GENERALES. 2.1.A) La promocion y el fomento del turismo: ¿dos términos similares? 2.1.B) Características y técnicas de promoción del turismo. 2.2. EL CARÁCTER EXTRATERRITORIAL DE LA PROMOCIÓN TURISTICA. TRATAMIENTOY $Y$ PROBLEMÁTICA CONSTITUCIONAL. 2.3. TÉCNICAS FUNCIONALES Y ORGÁNICAS PARA LA PROMOCIÓN DEL TURISMO. A) Medidas de fomento orgánicas. B) Medidas de fomento fincionales. 3. LA ORDENACIÓN DEL TURISMO. 4. INCIDENCIA DE OTROS TÍTULOS GENERALES Y SECTORIALES EN MATERIA DE TURISMO.

\section{CONSIDERACIONES GENERALES}

En la totalidad de las leyes autonómicas reguladoras del turismo se insiste en la importancia que éste tiene tanto en el sector económico como social y cultural y, sin embargo, pese a ello, el estudio de la ordenación del turismo ha sido una de las materias menos estudiadas por parte de nuestra doctrina administrativa. Ni la importancia que el mismo tiene para la economía española, ni la curiosa heterogeneidad y dispersión de su normativa reguladora, ni las contradicciones que resultan de la distribución competencial establecida en nuestra Constitución han llegado a constituir aspectos suficientemente poderosos como para llamar la atención e invitar a 
abundar en el estudio de esta materia en donde lo primero que resalta es la incomprensible falta de análisis doctrinal.

Pues bien, dentro de ese necesario análisis jurídico doctrinal una de las primeras tareas es la sistematización y ordenación de tan dispersa y abundante normativa existente en la materia y, de otra parte, clarificar y despejar algunas contradicciones o algunas conclusiones erróneas cuya clarificación se revela precisa.

No cabe duda de que nos encontramos ante una materia multidisciplinar, por ser numerosos y abundantes los puntos de vista de que puede partirse para su análisis -jurídico, económico, empresarial...- y también heterogénea desde el que aquí nos interesa, por cuanto la normativa reguladora no sólo incide en variadísimos aspectos, como son los alojamientos turísticos, restaurantes y cafeterías, agencias de viajes, etc., sino que también es abundante en exceso. Posiblemente por eso resulta frecuente encontrarnos con recopilaciones legislativas de la materia que aúnan en un solo texto la normativa existente, pero sin incidir en su análisis.

Por ello, la dificultad con que nos enfrentamos a la hora de abordar el estudio de la distribución competencial del turismo y, por su derivación, su ordenación jurídico-administrativa trae su causa tanto en la variedad y dispersión de la normativa, como en la falta de estudios doctrinales que arrojaran cierta luz sobre el tema.

Pero, al mismo tiempo, esta dificultad no deja de suponer un gran acicate y una importante motivación para emprender una aproximación a su estudio. Estudio que necesariamente es incompleto por cuanto el turismo también incide en aspectos jurídicos no analizados aquí (medio-ambientales, urbanísticos, sanitarios, etc.), pues su extensión desbordaría nuestro propósito, por lo que dichos aspectos habrán de ser dejados para otra ocasión y lugar.

Por eso, siendo la competencia legislativa en esta materia fundamentalmente autonómica, son estas leyes el casi exclusivo y único material con que se ha hecho posible este estudio; una legislación de cuya lectura pueden extraerse de entrada dos consideraciones: Primero, que casi todas son de contenido abstracto, descriptivo y escasamente concreto o de virtualidad directamente operativa, y segundo, que la mayor parte de ellas muestran puntos básicos coincidentes, tales como las definiciones y clasificaciones de restaurantes, alojamientos hoteleros, apartamentos, etc., y otros divergentes, sobre todo, en lo relativo a la estructura orgánica y los mecanismos ideados en relación con la promoción turística.

$\mathrm{Ha}$ de advertirse, igualmente, que aun estando la normativa reguladora del turismo bastante apegada a lo concreto y dedicada al detalle de cada actividad turística, no obstante, nuestro propósito no se centra en el análisis de tal pormenorización y descripción, sino, por el contrario, en la deducción de cuantas conclusiones generales puedan extraer- 
se de tal normativa con la finalidad de aportar resultados útiles y de algún interés para nuestra disciplina.

La opción que se impone, por tanto, es ofrecer una visión global de tales subsectores, el análisis de las potestades administrativas que tal normativa - variada, dispersa y heterogénea- atribuye a las distintas Administraciones Públicas, y valorar, en fin, los resultados finales de la misma.

Es sabido que el artículo 148.1.18 de nuestro texto constitucional confía en exclusiva a las CC.AA. «la promoción y ordenación del turismo en su ámbito territorial». Pues bien, con independencia de lo que después se dirá con mayor abundamiento acerca del precepto, de su tenor ya pueden deducirse dos hechos concretos: Primero, que la CE no establece un mandato imperativo a cumplir necesariamente por las CC.AA., sino que se limita a brindarles esta posibilidad. Cosa que sucedió con cierta celeridad, ya que, curiosamente, quizás por su pujanza económica, ésta fue una de las primeras competencias cuya transferencia reclamaron las CC.AA. y fueron asumidas por todas ellas. Es por eso por lo que la normativa reguladora del turismo es principalmente autonómica.

Segundo, que lo anterior implica, como afirmábamos antes, la abundancia y dispersidad de la normativa existente.

A ello hay que añadir que las normas se suceden, se derogan y sustituyen con extraordinaria frecuencia, fruto y resultado de la naturaleza y carácter necesariamente cambiante de las circunstancias sociales, económicas y de todo tipo que concurren en la materia.

El turismo es, pues, un sector caracterizado, ante todo, por la falta de vocación de permanencia de su normativa reguladora, por su gran variedad y, por qué no decirlo, por la improvisación con que se suceden los cambios, por cuanto éstos no se producen como consecuencia de las renovaciones normativas, sino justamente al revés. Las normas no son las incitadoras -en uno u otro sentido- de un determinado comportamiento incidente en el turismo, sino que éstas responden a la necesidad de regulación de los cambios que van produciéndose con independencia a la regulación existente en el momento.

No obstante, cuanto aquí se ha apuntado no puede sino ser provisional y transitorio ya que es ésta una de esas materias sobre las que más se legisla y, como signo de estos tiempos, a ritmos verdaderamente vertiginosos. Pues bien, hechas estas advertencias previas, hemos de partir en nuestro análisis del artículo 148.1.18 CE del cual derivan las dos grandes ramas jurídicas del turismo: su ordenación y promoción.

Es por ello por lo que toda la normativa de la materia turística -dicho sea en términos más usuales en nuestra disciplina-puede dividirse en normas de policía y normas de fomento, si bien en ambos casos, con ciertas matizaciones por parte de algunas leyes autonómicas como después veremos. La primera corresponde a la ordenación y las segunda a la promoción turística. 


\section{LA PROMOCIÓN TURÍSTICA}

\subsection{CONSIDERACIONES GENERALES}

\subsection{A) La promoción y el fomento del turismo: ¿dos términos similares?}

Como es bien sabido, JORDANA DE POZAS ${ }^{1}$ definía la actividad de fomento como la «acción de la Administración encaminada a promover o proteger aquellas actividades, establecimientos o riquezas debidos a los particulares y que satisfacen necesidades públicas, o que se estiman de utilidad general, sin usar la coacción, ni crear servicios públicos». Por su parte, S. MARTÍN-RETORTILLO ${ }^{2}$ la califica como «acción suasoria, estimulante, ejercida desde el Poder: determinación primero, e impulsión después, de actuaciones privadas que es de interés promover. Creencia, en definitiva, en los medios de acción indirectos para la satisfacción de algunas de las necesidades que se consideran de interés general; consecuentemente, protección, estímulo, auxilio, impulso de las actuaciones que tienden a satisfacerlas; fomento, por tanto, de tales actividades». En definitiva, cuantas definiciones pueden ofrecerse de actividad de fomento coinciden en afirmar que se trata de aquélla dirigida a impulsar y estimular determinadas actuaciones del sector privado por entenderlas de utilidad general y económica, contando, para ello con fórmulas concertadas de actuación con dicho sector. Pues bien, la indudable importancia que para la economía representa la actividad turística hace que la promoción del turismo sea una de las acciones administrativas de mayor relevancia cualitativa y cuantitativa del sector, porque, como afirma BAYÓN MARINÉ ${ }^{3}$, sin la comercialización y venta del producto turístico no se obtendrían los volúmenes económicos que han llevado al sector al primer puesto de los ingresos nacionales.

Al emprender el análisis del tan variado tratamiento que respecto de esta actividad administrativa ofrecen las Comunidades Autónomas que han legislado en esta materia, es preciso diferenciar con carácter previo dos términos que vienen siendo utilizados de manera indistinta como son el fomento y la promoción. Curiosamente la Constitución es-

1 L. JORDANA DE POZAS, «Ensayo sobre una teoría general del fomento en el Derecho Administrativon, Estudios de Administración local y general en honor de Jordana de Pozas I. Madrid, 1961.

2 S. MarTín-RETORTILlo, Derecho Administrativo Económico T. I., Madrid, La Ley, 1988, pp. 437 y ss.

3 F. Bayón Marinte, La Ordenación del Turismo. Madrid, Ed. Síntesis, 1992, p. 19. 
DA-2001, núms. 259-260. MARÍA JESÚS GALLARDO CASTILLO. La distribución constitucional de c...

pañola ha utilizado indistintamente ambos términos dentro de un mismo precepto como es el artículo 148. Así, en su apartado 13 se refiere al «fomento del desarrollo económico de la Comunidad Autónoma dentro de los objetivos marcados por la política económica nacional» y en el apartado 17, al «fomento de la cultura, de la investigación, y en su caso, de la enseñanza de la lengua de la Comunidad Autónoma». Por contra, los apartados 18 y 19 utilizan el término «promoción» para referirlo al turismo y al deporte y el ocio, respectivamente.

Ciertamente, la comprensión de tal distinción no es de fácil alcance. En un primer intento de acercamiento y de distinción de ambos términos podría utilizarse el criterio del modus operandi, el fin perseguido o la técnica empleada para dicha consecución. En este sentido, el fomento pudiera concebirse como un concepto más amplio que el de promoción en la medida en que aquél incluye a ésta. Así pues, siguiendo este criterio, podría entenderse que el género es el fomento y la promoción, la especie. De esta forma, y a salvo de alguna matización que con posterioridad se indicará, con base a lo establecido por alguna de la normativa autonómica dictada hasta el momento, el fomento podría venir referido al conjunto de técnicas, sobre todo económicas, encaminadas a la protección, estimulación de determinadas actividades, mientras que la promoción parece referirse a aquella acción de la Administración, sobre todo de carácter material, encaminada a dar publicidad a un determinado sector, ámbito o aspecto a fin de estimular, impulsar o potenciar una determinada actividad de los particulares.

Ahora bien, atendiendo a la utilización de ambos términos en nuestra Constitución española y, en general, en nuestro ordenamiento jurídico, o bien hay que entender que son sinónimos, sin que ningún dato diferenciador permita distinguirlos, o bien hubiera sido conveniente que, al referirse al turismo, la Constitución hubiera empleado el término «fomento» en vez de «promoción», pues la promoción del turismo no se ha limitado a la utilización de técnicas publicitarias de las Comunidades Autónomas en otras Comunidades Autónomas o en el extranjero, sino que también, y junto a ello, se ha extendido a otras técnicas de carácter económico, tales como subvenciones, premios, medallas, etc., como después veremos.

La referida distinción se complica en cuanto que, por su parte, la legislación autonómica tampoco utiliza a este respecto un criterio claro, en tanto que en algunas leyes autonómicas reguladoras del turismo se utilizan los dos términos tras un intento de diferenciación entre ellos, mientras que en otras se prefiere la utilización de uno de ellos eligiendo siempre el de «promoción», posiblemente por continuar con la terminología utilizada por la CE, obviando por completo el fomento. Otra posibilidad por la que han optado otras Comunidades Autónomas ha 
sido la de utilizar expresamente ambos términos indistintamente como si de sinónimos se tratara. La primera opción es la elegida por la Ley 3/1998, de 21 de mayo, de la Comunidad Valenciana, que reserva el término «promoción» para referirse tanto a la imagen turística como a la definición de los objetivos de las acciones concretas y de los instrumentos necesarios para el fortalecimiento y desarrollo del sector turístico. La Ley 1/1999, de 12 de marzo, de Ordenación del Turismo de Madrid, define en su artículo 41 la promoción turística como «el conjunto de actividades y medios a través de los cuales la Consejería competente en materia de turismo, favorece la demanda de servicios turísticos en la Comunidad de Madrid y apoya la comercialización de los productos turísticos regionales en el ámbito nacional e internacional». Por su parte, el artículo 46 define el fomento como «la actividad encaminada a la potenciación de la oferta turística de la Comunidad de Madrid a través de medidas concretas tendentes a la mejora de la competitividad, el empleo y la internacionalización de las empresas y sus profesionales». Pese a la aparente similitud de ambas definiciones ya pueden extraerse algunas consecuencias que nos permiten diferenciarlas: con el término promoción se hace referencia a la demanda mientras que con el fomento se pone el énfasis en la oferta. Mediante el primero se favorece la demanda a través del ofrecimiento de productos de calidad al mejor precio, planificación de visitas de interés cultural o de ocio, etc., y mediante el segundo, se potencia la oferta a través de la publicidad precisa en los distintos medios de comunicación, etc.

La segunda opción es la utilizada por la Comunidad de Murcia en la Ley 11/1997, de 12 de diciembre, cuyo Preámbulo comienza a utilizar ambos términos para referirse a las medidas concretas a utilizar para después, en los artículos 48 y siguientes, regular únicamente la promoción. Y lo mismo hace la Ley 6/1994, de 16 de marzo, de Ordenación del Turismo del País Vasco en el artículo 53 y la Ley Andaluza 12/1999, de 15 de diciembre, del Turismo, en su artículo 19.

Entre las leyes que utilizan los términos con similares significados destaca la Ley 8/1999, de 26 de mayo, de Castilla-La Mancha, la Ley 2/1997, de 20 de marzo, de Turismo de Extremadura, la Ley 10/1997, de 19 de diciembre, de Ordenación del Turismo de Castilla y León, y la Ley 5/1999, de 24 de marzo, de Ordenación del Turismo de Cantabria.

En definitiva, nos encontramos ante una variedad de posibilidades conceptuales que si bien no resultan relevantes ni posiblemente tengan una transcendencia práctica notoria, sin embargo, sirven para poner de manifiesto la diversidad de tendencias que encontrarán su traducción práctica en ciertas manifestaciones concretas, así como en la elección de medidas a adoptar para hacer efectivos tanto los principios como los objetivos previamente señalados. 
DA-2001, núms. 259-260. MARÍA JESÚS GALLARDO CASTILLO. La distribución constitucional de c...

\subsection{B) Caracteristicas y técnicas de promoción del turismo}

Desde el punto de vista jurídico, resulta preciso señalar que -a salvo algunas matizaciones derivadas de la singularidad de la actividad turística en cada una de sus manifestaciones y de aquellas propias de la técnica utilizada-, resultan predicables a la promoción del turismo las consideraciones y características que la doctrina y jurisprudencia suele cifrar con carácter general a la acción administrativa de fomento.

Haciendo un gran esfuerzo de síntesis podríamos concretar las notas características en las siguientes:

$1{ }^{a}$ Resulta especialmente frecuente que en el ámbito turístico resulte aplicable el llamado (VILLAR PALASÍ) principio de intercambiabilidad o convertibilidad de las distintas técnicas de fomento, de tal modo que podrían resultar de aplicación más de una para la consecución del fin que se pretenda ${ }^{4}$.

2. ${ }^{2}$ Lo más frecuente en materia turística es que se prevea la utilización de varias de ellas, si bien en muchos supuestos se establece claramente la preferencia por una de las posibles técnicas susceptibles de utilizarse.

Por lo general son medidas de distinta naturaleza las que se enuncian según qué actividad concreta pretende incentivarse dentro de la turística general.

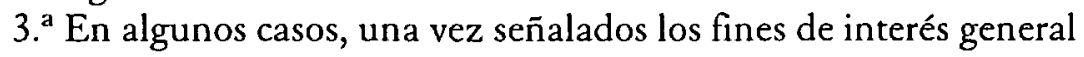
a promocionar, se enuncian las técnicas, a veces con la misma inconcreción, tratando de promover la realización de determinadas actuaciones.

Eso sucede, por citar un ejemplo, en la Ley 3/1998, de 21 de mayo, de la Comunidad Valenciana, en cuyo artículo 22 se señalan los objetivos entre los que destacan la divulgación de los recursos turísticos, la diversificación de la imagen turística de la Comunidad y la eficacia y competitividad de los productos turísticos. El artículo 23 establece otros objetivos fundamentales, tales como consolidar la Comunidad Valenciana como uno de los principales destinos turísticos, propiciar el crecimiento de la actividad turística y determinar e impulsar mecanismos para la desestacionalización de la actividad turística. Ya, por último, los artículos 23 y 24 señalan los instrumentos de la promoción turística y las acciones de promoción turística. Entre los primeros prevé el establecimento de Programas específicos adecuados a tales objetivos y entre las segundas, la realización de Jornadas de promoción, asistencias a Ferias, etc.

Algo similar, aunque con sustanciales diferencias en cuanto a la elección de las medidas a adoptar, es lo que sucede en la Ley 5/1999, de

4 A mayor abundamiento, vid. S. MARTín-RETORTILLO, Derecho Administrativo Económico, op. cit., pp. 442-443. 
24 de marzo, de Turismo de Cantabria, en cuyo artículo 42 se establecen, muy genéricamente, los principios de la promoción turística, regulándose de manera más pormenorizada las técnicas a utilizar entre las que destacan las Fiestas de Interés turístico, los Centros de Iniciativa Turística y el Fomento de los Estudios Turísticos.

Como puede fácilmente observarse, primero, no se establecen los mecanismos concretos encaminados a la consecución de los fines allí señalados, con lo que la discrecionalidad de la Administración es notoriamente amplia; segundo, medios y fines se confunden y mezclan de tal modo que no se sabe con certeza cuál es uno ni otro.

4. ${ }^{2}$ No puede olvidarse que la utilización de determinadas técnicas de fomento, sobre todo, las de carácter económico (tales como subvenciones, exenciones, etc.) suelen constituir un título habilitante que permite a la Administración ordenar y controlar las actuaciones que promociona.

Así, por ejemplo, la concesión de créditos subvencionados para establecimientos turísticos, o de subvenciones a los alojamientos y núcleos y zonas rurales, explican, con toda lógica, la fiscalización que la Administración pueda realizar en relación con los objetivos para cuya consecución fueron otorgadas las ayudas.

De esta manera, y con idea de empezar ya a deducir una conclusión global, puede afirmarse que, al igual que sucede con frecuencia en cualquier otro sector, en el turístico las medidas de fomento -sobre todo, las de carácter económico- llevan aparejada correlativamente la posibilidad de intervención en la actividad por parte de la Administración concedente, pudiendo ésta imponer un determinado comportamiento, una carga o una obligación en relación con la actividad que pretenda promocionar.

\subsection{EL CARÁCTER EXTRATERRITORIAL DE LA PROMOCIÓN TURÍSTICA. TRATAMIENTO Y PROBLEMÁTICA CONSTTTUCIONAL}

El ámbito espacial en que cada Comunidad Autónoma puede desarrollar sus competencias, en materia de turismo, suscita, al menos aparentemente, la necesidad de armonizar las previsiones constitucionales que se recogen respectivamente en los artículos 148.1.18 (ámbito territorial de la Comunidad Autónoma), 149.1.3 (relaciones internacionales) y 149.1.10 (comercio exterior).

El artículo 148.1.18 CE otorga competencia exclusiva en favor de las Comunidades Autónomas, limitando el ejercicio de la misma a su ámbito territorial. De hecho, todos y cada uno de los Reales Decretos sobre traspaso de funciones y servicios del Estado a las Comunidades Autónomas en materia de turismo suelen recoger como propia del Es- 
DA-2001, núms. 259-260. MARÍA JESÚS GALLARDO CASTILLO. La distribución constitucional de c...

tado la competencia de promoción turística fuera del territorio de la Comunidad Autónoma correspondiente.

Por citar un ejemplo, el R.D. 1.294/1984, de 27 de junio, sobre traspaso de funciones y servicios del Estado a la Comunidad Autónoma valenciana en materia de turismo, establece, en el apartado C) de su Anexo, que corresponderán al Estado las siguientes:

«a) Las relaciones internacionales, aunque, en tal caso, la Comunidad Autónoma será informada en la elaboración de Convenios Internacionales concernientes al turismo y adoptará las medidas necesarias para la ejecución de los mismos en lo que afecten a las materias atribuidas a su competencia.

b) La coordinación de la planificación general de la actividad turístịca.

c) (...)

d) La promoción y comercialización del turismo en el extranjero y las normas y directrices a las cuales se habrá de sujetar la Comunidad Valenciana cuando lleve a cabo actividades de promoción turística en el extranjero».

Y lo mismo se establece en el R.D. 3.585/1983, de 28 de diciembre, sobre traspaso de funciones y servicios del Estado a la Comunidad Autónoma de Andalucía, o el 3.080/1983, de 2 de noviembre, para Murcia, y así sucesivamente todos los demás.

Ahora bien, la inoperatividad o la incompleta operatividad que resultaría de la promoción del turismo en el propio territorio de cada Comunidad Autónoma hace que éstas requieran efectuarlo fuera de sus límites territoriales, procurando su fomento ya no sólo en el ámbito territorial de otras Comunidades Autónomas, sino también incluso fuera del territorio nacional.

Y así comenzó la primera polémica entre el Estado y las Comunidades Autónomas:

Como ha afirmado BAYÓN MARINÉ 5 , «mientras la Administración del Estado pretendía mantener en exclusiva esta competencia alegando fundamentalmente el contenido de la cláusula 10 del artículo 149.1. de la Constitución, las Administraciones autonómicas mantenían que la verdadera naturaleza de la promoción turística radica en la promoción exterior, y al tener claramente transferida la competencia de promoción turística, se entendía que abarcaba a todas las actividades propias de ésta. El problema se fue resolviendo poco a poco y más por la vía de los hechos que por la vía del Derecho. En tal sentido, las Comunidades

${ }^{5}$ F. Bayón Marine, Competencias en materia de Tutrismo, Madrid, Ed. Síntesis, 1992, p. 16. 
Autónomas empezaron a asistir a ferias internacionales y a realizar viajes de promoción al extranjero. Tras una época de conflicto con la Administración Central, se tomó una actitud laxa sobre la cuestión que consolidaba tácitamente la iniciativa tomada. La práctica se había impuesto sobre una cuestión cuya lógica respaldaba la avalancha imparable de actividades programadas y al fin, llevadas a cabo».

Quizá a causa de ello numerosas Leyes autonómicas han optado por obviar de forma ostensible esta cuestión, otorgando en consecuencia a la propia Comunidad Autónoma la competencia para promocionar su turismo tanto "fuera como dentro" de la propia Comunidad. Así, por ejemplo, la citada Ley de Turismo de Valencia prevé esta posibilidad en dos preceptos: en el artículo 22.2.d) establece entre los objetivos fundamentales «potenciar las acciones de promoción de la oferta turística de la Comunidad Valenciana, y sus distintas marcas y productos turísticos, dentro y fuera de su ámbito territorial», y el artículo 24.b) establece entre sus medidas concretas «la realización de Jornadas de promoción y la asistencia a ferias, tanto a nivel nacional como internacional». Lo mismo hace la Ley 10/1997, de 19 de diciembre, de la Comunidad Autónoma de Castilla y León, en su artículo 35.1 que establece de forma indubitada que «corresponde a la Administración de la Comunidad Autónoma el fomento y la planificación del turismo en su ámbito territorial, para promocionarlo dentro y fuera del mismo, así como para coordinar las actuaciones que en esta materia realicen otros organismos». Más claramente aún se expresa la Ley de Cantabria 5/1999, de 24 de marzo, en cuyo artículo 3 asigna a la Consejería sin ningún tipo de reticencias la competencia para fomentar su turismo a nivel autonómico, nacional e internacional. En idénticos términos se expresa el artículo 56 de la Ley 2/1997, de 20 de marzo, de Extremadura, si bien lo hace añadiendo que «sin perjuicio de las competencias del Estado». Esta misma fórmula es la utilizada por la Ley murciana 11/1997, de 12 de diciembre, quizás debido a las dificultades que entraña la distribución competencial en este extremo, establece en su artículo 48.1 que la promoción del turismo fuera del territorio nacional lo hará «de modo concertado con la Administración del Estado». Iguales términos utiliza la Ley 6/1994, de 16 de marzo del País Vasco.

Ahora bien, en esta materia no se ha decantado el TC con un criterio claro.

Cierto es que la Sentencia 125/1984, de 20 de diciembre, que resolvía el recurso interpuesto por las Comunidades Autónomạs de Cataluña, Canarias y Valencia contra el R.D. 2.288/1983, de 27 de julio-que establecía como medida de promoción hotelera la distinción «Recomendado por su calidad»- al analizar la incidencia de los apartados 10 y 13 del artículo 149.1 CE respecto a la promoción turística acabó por reconocer como autonómica tal competencia. 
Pero lo cierto es que lo hizo con ausencia de criterios generales, pues todo es cuestión de ponderación, de casuismo, de criterios cuantitativos, en definitiva, de lo espectacular y cuantioso de la medida, es decir, de su mayor o menor entidad económica, y no de lo que objetivamente establecen los artículos 148 y 149 CE.

Los términos textuales de la sentencia así parecen indicarlo cuando en relación a la incidencia en materia turística del apartado 13 del artículo 149.1 afirmaba que:

«el art. 149.1.13 de la Constitución no puede ser aplicable en este caso, pues (...) la competencia contenida en el RD 2288/1983 no puede en modo alguno tener carácter básico, ya que se trata de una medida de escasa entidad económica y de alcance sumamente reducido incluso entendida como mecanismo de promoción turística».

Y lo mismo afirma respecto a la incidencia del comercio exterior en la promoción turística:

«Una vez más, la posible concurrencia imperfecta de títulos dice el TC-obliga al intérprete del bloque de la constitucionalidad y de la norma o normas constitutivas del objeto de un conflicto a una tarea de ponderación difícilmente conceptualizable y, por fuerza, casuística. En el caso que nos ocupa, el objeto directo de la norma impugnada es el turismo y los efectos que su ejecución pudieran producir en el comercio exterior serían indirectos y de escasa entidad. La finalidad de la norma, en cuanto la vincula sólo débilmente en el comercio exterior, debe ceder en este caso frente a su contenido material, esto es, obliga a interpretarla como norma que disciplina la actividad turística».

De todo ello ya pueden deducirse varias consecuencias: de un lado, el alcance limitado de las potestades autonómicas en cuanto a la promoción de su turismo, y correlativamente, pese al silencio que el artículo 149.1 CE guarda en esta materia, las amplias posibilidades de actuación del Estado gracias a la incidencia que en ella mantienen las enumeradas en el artículo 149. Y de otro lado, la importante relativización en materia de promoción turística que sufre-necesariamente-el principio de territorialidad.

Pero a pesar de la existencia de criterios de mayor entidad y relevancia que el territorial, nuestra CE sigue bastante apegada a este último, cuando no deja de existir una contradictio in terminis entre la promoción del turismo y la imposición de confinarlo dentro de las fronteras donde ejerce sus competencias la Comunidad Autónomå correspon- 
diente, pues tal restricción choca con la propia finalidad de la actividad promocional turística que, para su efectividad, exige una proyección extraterritorial, pues carecería de sentido promocionar el turismo sólo en el lugar donde aquél se genera.

En cuanto a las fórmulas que la Administración puede utilizar para la consecución efectiva de esta promoción del turismo son muchas y no para todas ellas resulta predicable esta importante matización del principio de territorialidad. Entre otros instrumentos se encuentran la concesión de ciertas distinciones, tales como medallas, premios y diplomas, en cuyos supuestos suele regir el principio de territorialidad en todo su rigor sin que ello menoscabe en absoluto la eficacia de tal actividad promocional.

Así pues, para evitar generalizar, podría afirmarse que sólo en aquellos casos en que la promoción del turismo se realice a través de actuaciones materiales concretas, tales como dar publicidad de ciertos aspectos del turismo de una región, el principio de territorialidad ha de ceder en aras de la efectividad real de dicha actividad promocional de carácter material.

\subsection{TÉCNICAS FUNCIONALES Y ORGÁNICAS PARA LA PROMOCIÓN DEL TURISMO}

Hemos afirmado anteriormente que las Comunidades Autónomas han hecho uso de una amplia discrecionalidad en materia de promoción de su turismo poniendo de manifiesto cada una de sus tendencias optando por las muy diversas posibilidades de actuación. Aparte del establecimiento de distintas medidas promocionales del turismo a través de los distintos Decretos que las Comunidades Autónomas han ido dictando, han sido las propias Leyes de turismo las que han ido poniendo de manifiesto sus preferencias en cuanto a la elección de tales medios, los cuales admiten una clasificación dual en tanto que unos son de carácter funcional mientras que otros son orgánicos, aunque ambas son compatibles. Entre los primeros destacan la creación y concesión de distinciones como medallas y diplomas turísticos o el otorgamiento de subvenciones y premios. Entre las medidas orgánicas se encuentran la creación de asociaciones y sociedades anónimas ideadas con el fin de promocionar el turismo, posiblemente con la finalidad de eludir el principio de territorialidad antes referido. Veamos por Comunidades Autónomas:

\section{A) Medidas de fomento orgánicas}

La Ley 11/1997, de 12 de diciembre, de la Comunidad Murciana, reservó al Consejo Asesor de Turismo la política de promoción turística 
DA-2001, núms. 259-260. MARÍA JESÚS GALLARDO CASTILLO. La distribución constitucional de c...

en colaboración con las Corporaciones locales y con los agentes implicados. Por su parte, la Ley 5/1999, de 24 de marzo, de Cantabria, realizó una regulación completa de este tipo de medidas, creando con esta finalidad la Dirección General de Turismo y la Sociedad de Turismo de Cantabria, asignándole a ambas la promoción del turismo y el fomento de la comercialización, pudiendo ejercitar tales competencias bien directamente o en colaboración de otras entidades públicas o privadas (artículo 41). Con menor asignación competencial pero de gran relevancia crea también los Centros de Iniciativa Turística en el artículo 44, definiéndolos como entidades sin fines de lucro promovidas por asociaciones, fundaciones o particulares interesados en el sector para la promoción y fomento del turismo en un ámbito territorial delimitado. Estos Centros se rigen por los Estatutos de su constitución y tendrán, en todo caso, como finalidad primordial el desarrollo y promoción de los valores turísticos de su ámbito de actuación que podrá ser local, comarcal o autonómico. Se adscriben a la Dirección General de Turismo y deberán inscribirse en el Registro que al efecto se establezca por la Dirección General, la cual tendrá sobre ellos no sólo funciones de autorización sino también de información, o incluso funciones de gravamen tales como el control, inspección, sanción e incluso de revocación de las autorizaciones. Para hacer efectivas tales funciones estos Centros deberán remitir anualmente a la Dirección General de Turismo memoria detallada de todas las actividades así como las actas de sus órganos rectores y demás circunstancias que afecten a su funcionamiento.

La Comunidad Autónoma de Castilla y León, en el artículo 43.2 de la Ley 10/1997, de 19 de diciembre, creó las Oficinas de Turismo, al mismo tiempo que deja una amplia posibilidad de creación de organismos de muy distinta índole al prever el fomento del asociacionismo sin ánimo de lucro que tenga por finalidad, de una parte, la promoción y divulgación del turismo en su ámbito de actuación, y, de otra, el estudio e investigación del turismo en su Comunidad. Este tipo de medidas se establece con similitud de criterios en los artículos 42 y siguientes de la Ley 8/1999, de 26 de mayo, de Castilla-La Mancha. Como vemos, las citadas Leyes crean las Oficinas de Turismo pero no acometen su concreta definición que sí aparece fijada en la Ley 12/1999, de 15 de diciembre, del Turismo de Andalucía, que les encomienda la finalidad de facilitar al usuario orientación, asistencia e información turística. Esta Ley también prevé la creación de los siguientes órganos y entidades en materia de turismo que estarán adscritos a la Consejería competente en materia turística: el Consejo Andaluz de Turismo como órgano consultivo y de asesoramiento de la Junta de Andalucía en el que estarán representadas las entidades locales andaluzas, las organizaciones empresariales y sindicales más representativas y cuantas otras se determinen reglamentariamente. En 
segundo lugar, el Consejo de Coordinación Interdepartamental en materia de Turismo que es el órgano de coordinación y consulta interna de la Administración andaluza. En él quedarán representadas las distintas Consejerías cuyas materias tengan relación directa o indirecta con la actividad turística. La Oficina de Calidad del Turismo que tendrá por finalidad velar por la efectividad y garantías de los derechos de los turistas y garantizar la calidad de los servicios turísticos de Andalucía. Por último, la Escuela Oficial de Turismo que es el órgano que ejerce las competencias de la Consejería en materia de fomento, coordinación, colaboración y estudio de la formación en materia turística.

Fuera de estas Leyes autonómicas, e incluso con anterioridad a ellas, fueron creados distintos órganos de fomento y promoción mediante la utilización de la figura del Decreto. Por su trascendencia destacan algunos como el «Consorcio de Promoción Turística de Cataluña», creado por el Decreto 13/1986, de 16 de enero. Este Consorcio es una entidad dotada de personalidad jurídica, sometida al ordenamiento jurídico público y cuyos fines se concretaron en la ejecución de acciones de promoción turística y la prestación de asistencia técnica en materia de promoción turística a los entes que lo solicitaran. En la Comunidad Autónoma de Galicia fue creada en el año 1991 mediante el Decreto 198, de 27 de marzo, la llamada «Sociedad de Imagen y Promoción Turística de Galicia, S.A.» (TURGALICIA, S.A.). Esta Empresa tenía naturaleza pública aunque con participación de capital privado, y como objeto colaborar en la promoción de la oferta turística de Galicia en los mercados nacionales e internacionales, coordinando las acciones y fomentando las actividades del sector turístico gallego. Algo parecido sucede en Valencia donde, desde 1985, por virtud del Decreto 151, de 4 de octubre, se creó una sociedad anónima con personalidad jurídica propia y plena capacidad jurídica y de obrar con la finalidad de fomentar el turismo, a la que se denominó «Institut Turistic Valenciá, S.A.» (ITVA, S.A.). Del mencionado Decreto y de otro posterior, el 16/1992, de 3 de febrero, pueden deducirse las siguientes funciones: el estudio y análisis de la infraestructura turística de la Comunidad Autónoma valenciana, la potenciación de la oferta turística, la iniciativa de nuevas actividades turísticas, la difusión de información, realización de cursos, de actividades de cooperación, concesión de subvenciones y, en general, cuantas actividades contribuyan al mejor desarrollo de esta Comunidad Autónoma.

\section{B) Medidas de fomento funcionales}

Por otra parte, la legislación autonómica en materia de promoción de su turismo es extensa y variadísima, desbordando, desde luego, el 
DA-2001, núms. 259-260. MARÍA JESÚS GALLARDO CASTILLO. La distribución constitucional de c...

objeto de este trabajo el estudio y análisis de su contenido. Sirva a título de ejemplo, y a efectos de hacernos idea de los instrumentos utilizados por las distintas Comunidades Autónomas para promocionar su turismo, las previsiones incluidas en las siguientes leyes autonómicas: la Ley 12/1999, de 15 de diciembre, del Turismo de Andalucía, establece en sus artículos 19 a 21 una serie de medidas funcionales que tienen por finalidad el fomento y el mantenimiento de la imagen de calidad de Andalucía como destino turístico en los mercados que lo requieran. Sin perjuicio del desarrollo normativo posterior tanto por norma con carácter de ley como por instrumentos normativos de rango inferior a ella y sin perjuicio de aquellos instrumentos ideados con anterioridad a esta Ley si no se oponen a ella, aquí se establece una clara preferencia por dos instrumentos de fomento concretos: las declaraciones de interés turístico nacional de Andalucía y los incentivos de calidad. Con las primeras se pretende el reconocimiento de especial atractivo turístico a aquellas fiestas, acontecimientos, rutas y publicaciones que supongan una manifestación y desarrollo de los valores propios y de tradición popular. Con los segundos se persigue el reconocimiento de calidad mediante el otorgamiento de medallas, premios y galardones ${ }^{6}$. La Ley de Castilla y León 10/1997, de 19 de diciembre, ha previsto la realización de Programas de calidad de la oferta para favorecer la mejora y modernización de instalaciones y servicios turísticos así como la adopción de sistemas homogéneos para la evaluación de la calidad, Programas de formación turística para fomentar la cualificación de los profesionales del turismo mediante becas y otras ayudas y Programas de promoción y difusión con la finalidad de definir y fomentar una imagen de calidad de la Comunidad Autónoma. Junto con estos Programas se establece en el artículo 45 las ayudas y subvenciones a favor de aquellas empresas turísticas, Corporaciones locales y otras entidades y asociaciones como medidas para estimular la realización de las acciones fijadas en los programas de promoción y fomento del turismo. Con esta misma dicción se expresa el artículo 44 de la Ley 8/1999, de 26 de

${ }^{6}$ Con anterioridad a esta Ley en Andalucía ya se habían dictado normas al respecto: por ejemplo, la Orden de 31 de octubre de 1984 convocaba concurso de subvenciones para el fomento y desarrollo de ofertas turísticas especializadas, la Orden de 28 de noviembre de 1985 convocaba a concurso premios al embellecimiento y mejora de las playas andaluzas. Lo mismo lo hacía la Orden de 23 de marzo de 1984 ampliando en este caso su ámbito de aplicación a los pueblos de Andalucía. La Orden de 27 de noviembre de 1984 regulaba créditos subvencionados para establecimientos turísticos y la de 3 de octubre de 1986 establecía el procedimiento para la concesión de subvenciones a las Diputaciones Provinciales y Corporaciones Locales para la promoción turística. Más subvenciones fueron previstas en la Orden de 24 de noviembre de 1987, en la de 27 de septiembre de 1988, 18 de abril de 1989, 5 y 19 de abril de 1990, 1 de marzo y 27 de noviembre de 1991, y 23 de marzo de 1994, entre otras. 
mayo, de Castilla-La Mancha, si bien amplía su abanico de posibilidades al establecer los siguientes tres tipos de medidas de carácter funcional para la promoción de su turismo: de una parte, los incentivos, entendiendo por tales las medallas, premios, galardones y distinciones en reconocimiento y estímulo a las actuaciones a favor del turismo en general y del turismo en la Comunidad Autónoma en particular; de otra, las Fiestas de Interés Turístico regional que son todas manifestaciones concretas y determinadas, de naturaleza cultura, popular, etc., que comporten especial importancia como atractivo turístico; y, por último, las denominaciones geoturísticas mediante la selección y señalamiento de aquellos itinerarios turísticos o rurales, áreas concretas y determinadas localidades, comarcas o términos municipales que se entiendan de especial relevancia turística a fin de promocionar y fomentar visitas a todos ellos. La Comunidad murciana, por su parte, establece en su Ley 11/1997, de 12 de diciembre, medidas parecidas, tales como el establecimiento de Programas de Fomento o la posibilidad de calificar determinados proyectos empresariales como de Interés Turístico Regional. La Ley de Madrid 1/1999, de 12 de marzo, establece también la posibilidad de estimular el turismo mediante los incentivos de calidad y declaración de fiestas de interés turístico.

No son tan prolijas en la determinación de tales medidas funcionales las Leyes de la Comunidad Valenciana, la del País Vaco, ni de la Comunidad de Extremadura en las que más que fijarse instrumentos concretos de promoción y fomento se establecen objetivos a cumplir. Destaca por su originalidad la Ley 2/1999, de 24 de marzo, de las Islas Baleares, ya que no regula ni establece medidas concretas del fomento de su turismo sino que manifiesta especial preocupación por la calidad de los servicios que se presten. Por ello, en el capítulo dedicado al fomento del turismo se establecen determinadas medidas que tienen por finalidad el fomento de la calidad a través del ejercicio de actividades de policía, más concretamente, a través de la necesidad de solicitar autorizaciones y del adecuado desempeño de la actividad inspectora sobre el objeto de autorización.

\section{LA ORDENACIÓN DEL TURISMO}

Más compleja y heterogénea, si cabe, es la normativa reguladora de la ordenación del turismo.

Para empezar, puede afirmarse, con BAYÓN MARINÉ ${ }^{7}$ que el término «ordenación» puede tener multitud de acepciones, «cada una de las

\footnotetext{
${ }^{7}$ F. BAYÓN MARINÉ, Ordenación del Turismo, op. cit., p. 19.
} 
DA-2001, núms. 259-260. MARÍA JESÚS GALLARDO CASTILLO. La distribución constitucional de c...

cuales da un nuevo aspecto al concepto, unificándolo y complementándolo: ordenación es disposición y prevención, pero también es colocación de las cosas en el lugar que les corresponde y es también la regla, orden, mandato o precepto y también parte de la composición de un todo».

Por eso la ordenación turística tiene mucho que ver con la «buena disposición de la infraestructura turística, combinando el suelo, la naturaleza, la edificación, el objeto y la finalidad», pretendiendo su unificación para cada realización turística.

Es bien sabido que los países turísticos y, más en concreto, nuestro país, han sido protagonistas de un crecimiento desordenado y rápido que ha roto el entorno ecológico en favor de la expansión constructiva y en muchas ocasiones ha provocado profundos desajustes urbanísticos, sanitarios y sociales. Todo ello producto de la falta de previsión de una normativa que ordenara con antelación las actividades esporádicas y espontáneas que iban sucediéndose quizá de forma irreflexiva, quizá con criterios diferentes o en virtud de un orden distinto de intereses. prioritarios a los mantenidos en la actualidad.

Lo cierto es que la ordenación turística, entendida como conjunto de normas jurídicas reguladoras del sector, data de los años setenta en adelante, siendo toda ella posterior al crecimiento espontáneo del turismo, cuyo desarrollo, por tanto, fue produciéndose con independencia y a pesar de la gran deficiencia de normativa al respecto, con las consiguientes demoledoras consecuencias tanto en el aspecto urbanístico como medioambiental.

Por otra parte, cuando más proliferación normativa se produjo, sobre todo, con ocasión de la ordenación autonómica de la materia, en pocas ocasiones se ha buscado la unificación de criterios. Muy al contrario, cada Autonomía ha legislado libremente, provocando absurdas diferencias (en concreto, sobre calificación hotelera, subvenciones, complementos de turismo, etc.). Ha faltado, pues, no sólo un elemento coordinador, sino un afán de lógica identificación, proliferando así los inevitables desconciertos ${ }^{8}$.

La primera característica, por ello, que resulta predicable de la ordenación de nuestro turismo en su antecedente más inmediato es la gran heterogeneidad y la ausencia de criterios uniformes. Heterogeneidad que, en gran medida, queda salvada por demostrarse en toda ella una especial preocupación e incidencia en los mismos bienes jurídicos cuya protección se pretende con esta normativa: básicamente, consumidores y usuarios, la transparencia en los precios y la relación calidadprecio. Las previsiones autonómicas en materia de ordenación que se manifiestan y en cada una de las Leyes reguladoras del Turismo en las

${ }^{8}$ F. Bayón Mariné, Competencias..., op. cit., p. 16. 
Comunidades Autónomas que han legislado al respecto son aún más variadas y heterogéneas que las previstas en materia de promoción. Por ello la concreción de tales medidas en este trabajo excede su finalidad, por lo que aquí sólo van a extraerse conclusiones globales al respecto.

La primera conclusión que puede deducirse de la lectura conjunta de tal normativa autonómica es, como decimos, la gran heterogeneidad, la cual intentó salvarse por parte del Estado que no resistió la tentación de establecer una normativa general, por ejemplo, en materia de alojamientos turísticos con la finalidad de dar homogeneidad a la materia, pero sin la pretensión de que tal normativa fuera de preceptiva aplicación a las Comunidades Autónomas.

Por el contrario, aquéllas que regulasen la materia -como así ha sido-, sustituían con la misma el R:D. 1.634/1983, de 15 de junio, sobre Ordenación de los Establecimientos Hoteleros. Así pues, este RD suponía un simple punto de referencia respecto de las reglamentaciones autonómicas que pudieran darse, sin necesidad de que éstas debieran acomodarse a lo dispuesto en el mismo.

Algo parecido sucede respecto a los establecimientos extra-hoteleros. También en este caso existe una normativa estatal, a salvo, claro está, de lo que dispongan las CCAA, de las cuales, por cierto, son pocas las que han hecho uso de dicha posibilidad. En los supuestos de Comunidades Autónomas que no han dictado normativa al respecto les resulta de aplicación lo establecido en la normativa estatal, contenida fundamentalmente en la Orden de 17 de enero de 1967, la cual ha sido modificada parcialmente por el $\mathrm{RD} 2.887 / 1982$, de 15 de octubre. Esta normativa se caracteriza por su contenido definitorio y, sobre todo, clasificador de cada una de las modalidades de dichos establecimientos, al mismo tiempo que establecía determinados servicios mínimos a cumplir por cada uno de ellos.

El régimen de precios para alojamientos no fue, sin embargo, objeto de regulación por parte de la normativa mencionada. Para ellos seguían vigentes algunas Órdenes de fechas precedentes -actualizadas, por supuesto, después por cada Comunidad Autónoma- en las cuales se manifestaba una especial preocupación por la existencia de controles administrativos en cuanto a la fijación de precios y el establecimiento de algunos principios rectores que garantizaban los derechos de los usuarios, como son':

$\left.1^{\circ}\right)$ El principio de información, en virtud del cual, el cliente debe ser informado, antes de su admisión, del precio que se le va a aplicar.

$2^{\circ}$ ) El principio de especificidad, ya que deberán distinguirse con claridad los precios que corresponden a alojamiento y a las demás prestaciones que formen parte del funcionamiento normal del mismo.

9 Vid. Ramón ARCaRons SimÓN, Manual de Derecho Administrativo Turistico. Madrid, Ed. Síntesis, 1994, pp. 133 y 134. 
$\left.3^{\circ}\right)$ El principio de inalterabilidad durante el transcurso del año de su vigencia, si bien el cómputo de dicho año no se corresponde con el natural, sino que será distinto según donde esté establecido el alojamiento.

$\left.4^{\circ}\right)$ El principio de globalidad, por lo que los precios se componen de la suma del porcentaje destinado a personal, impuesto, tasas y arbitrios que estén legalmente autorizados.

Junto a los alojamientos turísticos, han sido también objeto de regulación las agencias de viajes, que lo fueron por vez primera en 1942, sucediéndose a partir de esa fecha distintas disposiciones, naturalmente, de carácter estatal.

Curiosamente, la asunción de esta competencia por parte de las Comunidades Autónomas no fue, desde luego, nada pacífica. Al contrario. Ante el temor de que cada Comunidad Autónoma regulara este subsector con absoluta falta de homogeneidad de criterios, la Administración estatal pretendía marcar las líneas directrices que aseguraran cierta unidad en su regulación. Las Comunidades Autónomas, por su parte, reclamaban para sí el ejercicio efectivo de esta competencia.

Pues bien, las principales modificaciones respecto de la normativa precedente se centraban, fundamentalmente en el establecimiento de una serie de requisitos administrativos para la obtención de la licencia de actividad y del funcionamiento de la Agencia ${ }^{10}$.

Junto a ello se observa una especial preocupación por la protección del cliente cuando se establece en los artículos 23 y 24 de la citada Orden que la publicidad editada por la Agencia de Viajes debe responder a criterios de precisión y veracidad, no pudiendo incluir publicidad falsa o engañosa, y debiendo informar a los clientes con carácter previo a la prestación de sus servicios el coste de los mismos. Curiosamente, pese a la existencia de una norma general de Protección del Consumidor de 1984, en cada regulación de los subsectores del turismo, se incide de forma singularizada en este mismo bien jurídico protegido.

En lo que hace a la inspección turística y régimen de sanciones, resulta preciso resaltar que a diferencia de lo que sucede con los demás subsectores del sector turístico en que, como se ha visto, las Comunidades Autónomas han venido legislando con posterioridad al Estado, siendo mucha de esa normativa autonómica copia casi literal de la normativa estatal, en materia de inspección turística y régimen de sanciones ha sucedido justamente al revés: la normativa estatal se encuentra recogida básicamente en el Decreto 235/1967, de 14 de enero. Por la propia fecha del Decreto no resulta difícil comprender que su contenido ha quedado obsoleto, por lo que las Comunidades Autónomas en la 
actualidad han ido asumiendo la competencia normativa en esta materia, aunque lo cierto es que lo han hecho todas ellas con un contenido bastante semejante o con unas diferencias poco significativas.

La normativa estatal respecto a la autonómica tiene carácter supletorio, y respecto a aquellas Comunidades Autónomas que aún no han legislado al respecto, pese a su falta de adecuación a la realidad del sector en la actualidad, se aplicará directamente.

\section{INCIDENCIA DE OTROS TÍTULOS GENERALES Y SECTORIALES EN MATERIA DE TURISMO}

Mayor complejidad que las cuestiones analizadas hasta el momento encierra la incidencia de otros títulos generales y sectoriales en materia de turismo. Después de la distribución de competencias establecida por la Constitución y como consecuencia de las distintas normas que la desarrollan existen en el sector turístico competencias concurrentes en los tres niveles de Administración española: Estatal, Autonómica y Local, y ello sin contar con la actividad aportada por la Unión Europea, que si bien hoy es escasa, ha de ser creciente a corto plazo.

La LRBRL en dos ocasiones hace partícipes a las entidades locales en la materia de turismo: De un lado, en el artículo 25.2.m, y de otro, en el artículo 30. En este último precepto lo hace posibilitando a las CCAA para que pueden establecer regímenes especiales para Municipios que reúnan características que lo hagan aconsejable, como es el predominio en su término de las actividades turísticas.

La previsión es lógica, sobre todo si se tiene en cuenta que la LRBRL realiza la distribución de competencias a los Municipios siguiendo el criterio del número de habitantes.

Siendo así, resulta que Municipios que tienen un número determinado de habitantes de derecho, ve acrecentado el número de habitantes de hecho durante ciertos meses en el año. Meses en que será necesario haber previsto y contar efectivamente con los servicios que el legislador ha entendido de preceptivo cumplimiento para los Municipios con dicho número de habitantes.

Así, como afirma CorNo CAPARRós ${ }^{11}$ los municipios turísticos, como consecuencia de la afluencia estacional o permanente (según se trate de turismo vacacional o residencial) de personas procedentes de otros lugares, sufren un desequilibrio entre su configuración de Derecho y su realidad de hecho.

$"$ L. CORNO CAPARROS, «El estatuto legal del municipio turístico», REDA, $\mathrm{n}^{\circ} 42,1984$, p. 427. 
DA-2001, núms. 259-260. MARÍA JESÚS GALLARDO CASTILLO. La distribución constitucional de c...

Ello supone la obligación de prestar unos servicios públicos irregulares en el tiempo, por su estacionalidad, y desproporcionada con los servicios que corresponderían a sus habitantes de derecho. Por ejemplo, servicios mayores de limpieza, desplazamientos a alrededores y aeropuertos, mayor atención a los servicios de hostelería y tratamiento y vigilancia de playas y costas...

Por ello, el artículo 30 LRBRL no deja de suponer una importante reacción contra el uniformismo característico de anteriores Leyes de régimen local ${ }^{12}$, pues ciertamente en aquellos Municipios en que predominan determinadas actividades turísticas resultará afectado tanto el modo de vida de sus habitantes como también se producirán determinadas repercusiones en el ámbito de actuación de los respectivos Ayuntamientos: la necesidad de contratar personal por tiempo limitado a la temporada turística, de buscar fuentes de financiación de la Hacienda local relacionadas con la verdadera riqueza del Municipio, o de proteger con mayores medidas el medio ambiente o prever determinaciones específicas de carácter urbanístico. La imposibilidad de determinar tales extremos en la LRBRL hace aconsejable que sean las CCAA quienes, en atención a las condiciones peculiares de los Municipios de su territorio, regulen con mayor precisión el régimen regulador de los mismos.

Pero el margen de maniobra que el artículo 30 LRBRL permite es relativamente escaso porque, o bien choca con los mínimos de la legislación estatal básica (órganos esenciales del Ayuntamiento, normas imperativas de funcionamiento establecidas en garantía de los administrativos, necesidad de ley estatal para autorizar la exacción de todo tributo), o bien puede alcanzarse la misma finalidad mediante la legislación que para desarrollo de esta misma Ley pueden dictar.

Lo curioso es que ni la LRBRL ni las Leyes específicas sobre Régimen Local dictadas por algunas Comunidades Autónomas han ofrecido especial atención al tema.

Fue pionera en su establecimiento la Ley 8/1987, de 15 de abril, de régimen local de Cataluña, que definía el Municipio turístico en su artículo 72 en consideración con el incremento del número de habitantes y la necesidad de prever el establecimiento y satisfacción de los servicios públicos adecuado con él. A esta Ley han seguido después otras muchas, como por ejemplo la reciente Ley 12/1999, de 15 de diciembre, del turismo de Andalucía.

Pero el problema que se plantea en el Municipio turístico no es solamente el ya apuntado, sino más bien, por una parte, la falta de regu-

12 Vid. Nuevo Regimen Local. El Consultor de los Ayuntamientos y de los Juzgados. Madrid, Ed. Abella, 1988, tomo I, p. 348. 
lación satisfactoria en la práctica totalidad de las CCAA, y de otra la descarnada (y descarada) especulación del sistema, de la política seguida en ellos de beneficio rápido, el desorden urbanístico, la creciente degradación medioambiental, y, en definitiva, la falta de relación calidad-precio, de infraestructura, y de previsiones para la protección del entorno natural y urbano del Municipio turístico.

Por lo que se refiere a la Administración Estatal, ha quedado de manifiesto el contenido del artículo $149 \mathrm{CE}$. La concurrencia de competencias estatales que de él deriva en la materia turística generó, como es lógico, algunos conflictos competenciales entre estos niveles territoriales, los cuales han dado lugar a algunos pronunciamientos del TC, en cuya respuesta final -después de algunos titubeos y de utilizar criterios no siempre objetivos, como se dijo anteriormente- acabó por afirmar algo tan lógico como que ni las CCAA pueden pretender que el Estado no se inmiscuya en la materia del turismo por la sencilla razón de que hay ámbitos o títulos competenciales en el artículo $149 \mathrm{CE}$ cuya relación con la materia turística resulta indudable; pero que tampoco el Estado puede pretender cualquier actividad que implique ejercicio de una competencia indeterminada o genérica en tanto ello pueda significar alteración del ámbito competencial de aquéllas o sustracción del que está reservado a ellas.

Es lo que sucede, por ejemplo, en temas de subvenciones (STC 75/1989, de 24 de abril): la mera previsión de estas subvenciones y la regulación genérica de sus condiciones corresponde al Estado por tener alcance nacional. Por el contrario, la convocatoria, concesión, gestión e inspección de dichas ayudas resulta ser competencia autonómica.

Lo mismo ocurre en cuanto a los títulos académicos (SSTC 83/84, $42 / 86$ y 122/89, de 6 de julio): la creación de una profesión titulada es competencia estatal por lo establecido en el artículo 149.1.30 CE, mientras que la determinación de las condiciones o de ciertos requisitos para ejercer una determinada actividad lo es autonómica.

Así sucede también con el seguro turístico, por ser una derivación concreta de la cláusula general establecida en el artículo 149.1.11 CE, cuando atribuye al Estado competencia exclusiva para las «bases de la ordenación del crédito, banca y seguros", o los transportes turísticos, la nacionalidad, inmigración, emigración, extranjería y derecho de asilo (art. 149.1.2), relaciones internacionales (art. 149.1.3), divisas y cambio y convertibilidad de la moneda (art. 149.1.11), marina mercante, puertos y aeropuertos de interés general (art. 149.1.20), o los museos de titularidad estatal (art. 149.1.23).

Como señala la STC 125/1984, de 20 de diciembre, «la posible concurrencia imperfecta de títulos obliga al intérprete del bloque de la constitucionalidad y de la norma o normas constitutivas del objeto de un 
conflicto, a una tarea de ponderación, difícilmente conceptualizable y, por fuerza, casuística».

En definitiva, esta "posible concurrencia imperfecta de títulos» permite sentar como conclusión inmediata la «universalidad» sólo teórica del poder de las Comunidades Autónomas en materia de turismo.

Así pues, la exclusividad con que parece ser atribuida esta competencia a las Comunidades Autónomas no es tal. Resulta tan sumamente improbable que la materia turística aparezca en toda «su pureza», es decir, sin guardar relación alguna con las materias de competencia reservada en exclusiva al Estado, que la regla general que resulta es que el Estado pueda ampararse en alguno de los títulos competenciales del artículo 149.1 CE para esgrimir su legitimación constitucional para incidir en la materia turística pese a que el silencio del artículo 149.1 CE respecto a ella pudiera dar lugar a entender, en principio, lo contrario.

La cuestión no es baladí, ni su resolución es de fácil alcance. Por otro lado, tampoco en este caso, como en otros muchos, aportan válidas soluciones las reglas generales.

Pero junto a esta gradación de los títulos competenciales como criterio determinante del ente -Estado o Comunidad Autónoma- que lo ostenta, otros dos criterios suelen servir de base para la solución del conflicto, tal y como se puso de manifiesto anteriormente:

Uno, la primacía de lo general sobre lo particular, y de lo general sobre lo especial. Otro, el que venimos denunciando a lo largo de este trabajo, el criterio cuantitativo, es decir, de la importancia económica de la medida, no establecido con este tenor en ninguna norma, pero sí aplicado de facto por el TC.

Por todo ello, en materia de turismo son muchos los extremos -sobre todo, en materia competencial- cargados de incertidumbre y en donde es bastante improbable que las reglas generales sirvan para despejar las dudas de que adolece.

Lo que sí está claro es que al TC le queda aún mucho por decir. Sólo cabe esperar que los futuros pronunciamientos del mismo aporten soluciones más loables sobre este tema cuya importancia no sólo es económica, sino también jurídica, lo cual hace menos disculpable la escasa atención dispensada por la doctrina a esta apasionante y trascendente materia. 
DA-2001, núms. 259-260. MARÍA JESÚS GALLARDO CASTILLO. La distribución constitucional de c...

DA-2001, núms. 259-260. MARÍA JESÚS GALLARDO CASTILLO. La distribución constitucional de c... 